\title{
BMJ
}

\section{Effect of $\beta$ blockers in treatment of chronic obstructive pulmonary disease: a retrospective cohort study}

\author{
Philip M Short, clinical research fellow respiratory medicine, ${ }^{1}$ Samuel I W Lipworth, medical student, ${ }^{2}$ Douglas \\ H J Elder, clinical research fellow cardiovascular medicine, ${ }^{3}$ Stuart Schembri, consultant respiratory \\ physician, ${ }^{4}$ Brian J Lipworth, professor of respiratory medicine ${ }^{1}$
}

${ }^{1}$ Asthma and Allergy Research Group, Centre for Cardiovascular and Lung Biology, Division of Medical Sciences, University of Dundee, Dundee DD1 9SY,

Scotland, UK

${ }^{2}$ Bute Medical School, University of St Andrews, St Andrews KY16 9UY, Scotland

${ }^{3}$ Centre for Cardiovascular and Lung Biology, Division of Medical Sciences University of Dundee

${ }^{4}$ Department of Respiratory Medicine, Perth Royal Infirmary, Perth PH1 1NX, Scotland

Correspondence to: B J Lipworth brianlipworth@gmail.com

Cite this as: BMJ 2011;342:d2549 doi:10.1136/bmj.d2549

\section{ABSTRACT}

Objective To examine the effect of $\beta$ blockers in the management of chronic obstructive pulmonary disease (COPD), assessing their effect on mortality, hospital admissions, and exacerbations of COPD when added to established treatment for COPD.

Design Retrospective cohort study using a disease specific database of COPD patients (TARDIS) linked to the Scottish morbidity records of acute hospital admissions, the Tayside community pharmacy prescription records, and the General Register Office for Scotland death registry.

Setting Tayside, Scotland (2001-2010)

Population 5977 patients aged $>50$ years with a diagnosis of COPD.

Main outcome measures Hazard ratios for all cause mortality, emergency oral corticosteroid use, and respiratory related hospital admissions calculated through Cox proportional hazard regression after correction for influential covariates.

Results Mean follow-up was 4.35 years, mean age at diagnosis was 69.1 years, and $88 \%$ of $\beta$ blockers used were cardioselective. There was a $22 \%$ overall reduction in all cause mortality with $\beta$ blocker use. Furthermore, there were additive benefits of $\beta$ blockers on all cause mortality at all treatment steps for COPD. Compared with controls (given only inhaled therapy with either short acting $\beta$ agonists or short acting antimuscarinics), the adjusted hazard ratio for all cause mortality was 0.28 (95\% Cl 0.21 to 0.39 ) for treatment with inhaled corticosteroid, long acting $\beta$ agonist, and long acting antimuscarinic plus $\beta$ blocker versus 0.43 ( 0.38 to 0.48 ) without $\beta$ blocker. There were similar trends showing additive benefits of $\beta$ blockers in reducing oral corticosteroid use and hospital admissions due to respiratory disease. $\beta$ blockers had no deleterious impact on lung function at all treatment steps when given in conjunction with either a long acting $\beta$ agonist or antimuscarinic agent

Conclusions $\beta$ blockers may reduce mortality and COPD exacerbations when added to established inhaled stepwise therapy for COPD, independently of overt cardiovascular disease and cardiac drugs, and without adverse effects on pulmonary function.

\section{INTRODUCTION}

The presence of cardiovascular disease and chronic obstructive pulmonary disease (COPD) are intertwined because of the risk of smoking induced atherosclerosis in patients with COPD. ${ }^{1}$ Despite the proved benefits of $\beta$ blockers in treating hypertension, ischaemic heart disease, and heart failure, many doctors are reluctant to prescribe $\beta$ blockers for patients with concurrent COPD. ${ }^{2}$

Historically $\beta$ blockers have been avoided in asthma because of the risk of acute bronchospasm. ${ }^{3-5}$ These concerns also apply to COPD, with evidence of a reduction in forced expiratory volume in one second $\left(\mathrm{FEV}_{1}\right)$, increased airway hyperresponsiveness, and inhibition of bronchodilator response to $\beta$ agonists in patients receiving non-selective $\beta$ blockers and high doses of cardioselective $\beta$ blockers. ${ }^{67}$

Despite these concerns, evidence suggests that cardioselective $\beta$ blockers do not cause an increase in exacerbations, reduction in airway function, or worsening of quality of life in COPD patients. ${ }^{8-10}$ COPD is a highly heterogeneous condition, and the degree of comorbidities present seems to be independent of the degree of airway obstruction. ${ }^{11}$ The treatment of comorbid cardiovascular disease in COPD is especially relevant since cardiac failure has been shown to be a leading cause of death in these patients. ${ }^{12}$

In this regard, the use of $\beta$ blockers in patients with COPD and cardiovascular disease has been shown to reduce mortality. ${ }^{1314}$ Whether the improved survival seen with $\beta$ blockers in COPD is purely due to cardiovascular effects has been questioned. Recent evidence suggests that $\beta$ blockers may improve survival and exacerbations even in COPD patients without cardiovascular disease. ${ }^{15}$

Although cardioselective $\beta$ blockers have been designed to target $\beta_{1}$ adrenoceptors while avoiding $\beta_{2}$ adrenoceptors in the lung and elsewhere, so called cardioselective $\beta$ blockers (such as atenolol and bisoprolol) are only relatively selective and exert significant $\beta_{2}$ antagonism at therapeutic doses, though to a lesser extent than non-selective $\beta$ blockers such as propranolol. ${ }^{16-19}$ Thus, it might be considered counterintuitive to prescribe both $\beta$ blockers and $\beta$ agonists in 
the same patient, even when they are targeting different organs.

Current COPD management guidelines advocate a stepwise approach using long acting bronchodilators (including $\beta$ agonists) and inhaled corticosteroids to reduce exacerbations and improve symptoms and lung function. With the exception of tiotropium, combination treatments involving long acting bronchodilators and inhaled corticosteroids have failed to show any significant improvement in mortality. ${ }^{2021} \mathrm{We}$ therefore wished to examine the use of $\beta$ blockers in the management of COPD, assessing their interactions with $\beta$ agonists and other COPD drug and assess whether they improve mortality, hospital admissions, and exacerbations when added to established treatment for COPD.

\section{METHODS}

We searched the NHS Tayside Respiratory Disease Information System (TARDIS) to identify patients from January 2001 to January 2010 with a diagnosis of COPD. TARDIS is a disease specific database developed in 2001 to support general practitioners and secondary care respiratory physicians in managing patients with COPD in Tayside, Scotland. Entry into TARDIS requires a diagnosis of COPD based on the Global Initiative for Chronic Obstructive Lung Disease (GOLD) guidelines. ${ }^{22}$ Data within TARDIS include patient demographics, respiratory symptoms, lung function, and smoking history. Data stored in the TARDIS database (including spirometry data) are collected at annual visits by specialist respiratory nurses who have received structured training in order to standardise results.

We searched data provided by the Health Informatics Centre, at the University of Dundee on behalf of the Information Services Division of NHS Scotland, using Scottish morbidity records to identify patients covered by the NHS Tayside Health Board who had had a hospital admission because of COPD. Discharge summaries with a diagnosis of COPD were used to identify respiratory related hospital admissions. Diagnoses were based on ICD-9 and ICD-10 codes (international classification of diseases, ninth and 10th revisions). The data held by the Health Informatics Centre undergo data quality checks before release.

We collected prescription data of respiratory and cardiovascular drugs from the Tayside Community Prescription database and records of deaths in our population from the General Register Office for Scotland. Each patient's deprivation index was based on their postcode and calculated with the Scottish Index of Multiple Deprivation (SIMD). A health board specific deprivation index (HBSIMD) was calculated in relation to the local population. A history of diabetes and admission to hospital for cardiovascular disease (including ischaemic heart disease, heart failure, and peripheral vascular disease) were identified from ICD-9 and ICD-10 codes.

\section{Data analysis}

Patients were initially divided into two groups dependent on $\beta$ blocker use. We performed Kaplan-Meier analysis with log rank testing to compare all cause mortality dependent on $\beta$ blocker use. Cox proportional hazard regression analysis was used to calculate crude and adjusted hazard ratios and their 95\% confidence intervals for all cause mortality associated with $\beta$ blocker use, and for cardioselective $\beta$ blockers and non-selective $\beta$ blockers. Adjusted hazard ratios were calculated after correction for the following covariates: cardiovascular and respiratory hospital admissions, diabetes, smoking, age, sex, and cardiac drug use (aspirin, statins, calcium channel blockers, and angiotensin converting enzyme inhibitors), $\mathrm{FEV}_{1}$ (as percentage of predicted value), resting arterial oxygen

\begin{tabular}{|c|c|c|c|c|c|c|c|c|c|}
\hline $\begin{array}{l}\text { Treatment } \\
\text { groups* }\end{array}$ & $\begin{array}{c}\text { No of } \\
\text { patients }\end{array}$ & $\begin{array}{l}\text { Mean (SD) age } \\
\quad \text { (years) }\end{array}$ & Male & $\begin{array}{c}\text { Mean (SD) } \\
\text { FEV }_{1} \dagger\end{array}$ & $\begin{array}{c}\text { Mean (SD) } \\
\mathrm{SaO}_{2} \ddagger\end{array}$ & $\begin{array}{c}\text { Mean (SD) } \\
\text { smoking pack } \\
\text { years }\end{array}$ & $\begin{array}{l}\text { History of } \\
\text { cardiovascular } \\
\text { disease }\end{array}$ & $\begin{array}{l}\text { History of } \\
\text { diabetes }\end{array}$ & $\begin{array}{c}\text { Mean (SD) } \\
\text { deprivation } \\
\text { index§ }\end{array}$ \\
\hline ICS & 464 & $69.7(9.8)$ & $239(51.5)$ & $65.5(19.5)$ & $94.2(10.9)$ & $41(16.5)$ & 190 (40.9) & $46(9.9)$ & $2.1(1.4)$ \\
\hline $\mathrm{ICS}+\mathrm{BB}$ & 71 & $71.7(8.6)$ & $36(50.7)$ & $64.2(16.1)$ & $93.3(14.5)$ & 39 (12.6) & $51(71.8)$ & $18(25.4)$ & $2.2(1.4)$ \\
\hline ICS+LABA & 996 & $68.9(9.6)$ & 547 (54.9) & $62.7(18.9)$ & $92.5(13.5)$ & $41.2(19.4)$ & $429(43.1)$ & $148(14.9)$ & $2.3(1.4)$ \\
\hline$I C S+L A B A+B B$ & 143 & $68.8(9.7)$ & $70(49)$ & $65.7(16.7)$ & $94.2(9.8)$ & $41.5(18.4)$ & $96(67.1)$ & $25(17.5)$ & $2.1(1.4)$ \\
\hline ICS+LABA+Tio & 1857 & $68.3(8.9)$ & 972 52.3) & $50.8(17.1)$ & $91.3(11.6)$ & $44.8(16)$ & $874(47.1)$ & 259 (13.9) & $2.2(1.3)$ \\
\hline $\mathrm{ICS}+\mathrm{LABA}+\mathrm{TiO}+\mathrm{BB}$ & 187 & $68.1(8.4)$ & $77(41.2)$ & $52.8(16.4)$ & $92.6(9.5)$ & 45.1(18.6) & $146(78.1)$ & $33(17.6)$ & $2.0(1.2)$ \\
\hline $\begin{array}{l}\text { LABA or Tio (no } \\
\text { ICS) }\end{array}$ & 526 & $69.9(9.2)$ & $263(50)$ & $60(17.4)$ & $93.5(7.9)$ & 45.7 (19.9) & $220(41.8)$ & $67(12.7)$ & $2.2(1.4)$ \\
\hline BB (no ICS) & 276 & $70.8(8.8)$ & $109(39.5)$ & $73.7(16.3)$ & $95.5(7.1)$ & $44.7(16.4)$ & $181(65.6)$ & $57(20.7)$ & $2.2(1.4)$ \\
\hline ICS+Tio & 158 & $69.1(9.2)$ & $70(44.3)$ & $55(16.6)$ & $93.2(9.5)$ & $44.1(19.7)$ & $73(46.2)$ & $25(15.8)$ & $2(1.3)$ \\
\hline (LABA or Tio)+BB & 119 & $70.1(8.1)$ & $48(40.3)$ & $63.5(14.2)$ & $95(2.1)$ & $48.6(22.3)$ & $84(70.6)$ & $32(26.9)$ & $2.2(1.4)$ \\
\hline Control group $\mathbb{~}$ & 1180 & $70.5(10.2)$ & $617(52.3)$ & $69.1(18.3)$ & $94.7(7.9)$ & $43.5(16.5)$ & $534(45.3)$ & $145(12.3)$ & $2.1(1.4)$ \\
\hline
\end{tabular}

*Treatments: ICS=inhaled corticosteroid, $B B=\beta$ blocker, $L A B A=$ long acting $\beta$ agonist, Tio=tiotropium.

$\mathrm{TFEV}_{1}=$ forced expiratory volume in one second, given as percentage predicted for age, sex, and race.

$\ddagger \mathrm{SaO}_{2}=$ Resting arterial oxygen saturation

§On a scale of 1-4 (1=most deprived, $4=$ =east deprived).

ПControl treatment only with short acting $\beta$ agonists or antimuscarinic agent. 
Table 2 |Effect of different treatment regimens* on $\mathrm{FEV}_{1} \dagger$ of patients with COPD during study period

\begin{tabular}{|c|c|c|c|c|}
\hline \multirow[b]{2}{*}{ Treatment groups ${ }^{\star}$} & \multicolumn{2}{|c|}{ Mean (SD) $\mathrm{FEV}_{1} \dagger$} & \multirow{2}{*}{$\begin{array}{l}\text { Mean difference }(95 \% \\
\mathrm{Cl})\end{array}$} & \multirow[b]{2}{*}{$P$ value } \\
\hline & First recording & Last recording & & \\
\hline ICS $(n=204)$ & $1.64(0.61)$ & $1.63(0.62)$ & $-0.01(-0.04$ to 0.03$)$ & 0.658 \\
\hline$I C S+B B(n=43)$ & $1.55(0.57)$ & $1.58(0.55)$ & $0.03(-0.05$ to 0.10$)$ & 0.459 \\
\hline ICS+LABA $(n=459)$ & $1.52(0.60)$ & $1.54(0.62)$ & $0.02(-0.01$ to 0.05$)$ & 0.123 \\
\hline ICS+LABA+BB $(n=89)$ & $1.55(0.54)$ & $1.57(0.55)$ & $0.03(-0.03$ to 0.08$)$ & 0.355 \\
\hline ICS+LABA+Tio $(n=753)$ & $1.22(0.51)$ & $1.19(0.51)$ & $-0.03(-0.06$ to -0.01$)$ & $<0.001$ \\
\hline ICS+LABA+Tio+BB $(n=88)$ & $1.27(0.50)$ & $1.28(0.53)$ & $0.01(-0.06$ to 0.08$)$ & 0.749 \\
\hline LABA or Tio (no ICS) $(n=197)$ & $1.48(0.58)$ & $1.44(0.57)$ & $-0.04(-0.08$ to -0.01$)$ & 0.016 \\
\hline BB (no ICS) $(n=276)$ & $1.83(0.53)$ & $1.74(0.55)$ & $-0.09(-0.11$ to -0.06$)$ & $<0.001$ \\
\hline ICS+Tio $(n=81)$ & $1.37(0.53)$ & $1.40(0.49)$ & $0.03(-0.03$ to 0.09$)$ & 0.257 \\
\hline$($ LABA or Tio)+BB $(n=47)$ & $1.67(0.56)$ & $1.65(0.57)$ & $-0.02(-0.09$ to 0.04$)$ & 0.435 \\
\hline Control¥ $(n=475)$ & $1.76(0.62)$ & $1.69(0.59)$ & $-0.07(-0.09$ to -0.05$)$ & $<0.001$ \\
\hline
\end{tabular}

*Treatments: ICS=inhaled corticosteroid, BB= $\beta$ blocker, $\mathrm{LABA}=$ long acting $\beta$ agonist, Tio=tiotropium. $+\mathrm{FEV}_{1}=$ forced expiratory volume in one second (litres).

$\ddagger$ Control=treatment only with short acting $\beta$ agonists with or without short acting antimuscarinic agent.

saturation $\left(\mathrm{SaO}_{2}\right)$, and deprivation index. We calculated a propensity score using covariates influencing $\beta$ blocker use and repeated the Cox regression model in a subgroup of patients matched on propensity score.

Patients were then divided into subgroups based on their maximal stepwise inhaled therapy and $\beta$ blocker use: inhaled corticosteroids (group 1); inhaled corticosteroids and long acting $\beta$ agonists (salmeterol or formoterol) (group 2); inhaled corticosteroids, long acting $\beta$ agonists, and $\beta$ blockers (group 3); inhaled corticosteroids, long acting $\beta$ agonists, and long acting antimuscarinic (tiotropium) (group 4); inhaled corticosteroids, long acting $\beta$ agonists, tiotropium, and $\beta$ blockers (group 5); long acting $\beta$ agonists or tiotropium (no inhaled corticosteroids) (group 6); $\beta$ blockers (no inhaled corticosteroids) (group 7); inhaled corticosteroids and $\beta$ blockers (group 8); inhaled corticosteroids and tiotropium (group 9); and $\beta$ blockers with either long acting $\beta$ agonists or tiotropium (group 10). The control group comprised those who had received

Table $3 \mid$ Effect of different treatment regimens* on FVC† of patients with COPD during study period

\begin{tabular}{|c|c|c|c|c|}
\hline \multirow[b]{2}{*}{ Treatment groups* } & \multicolumn{2}{|c|}{ Mean (SD) FVC $†$} & \multirow{2}{*}{$\begin{array}{l}\text { Mean difference }(95 \% \\
\text { (I) }\end{array}$} & \multirow[b]{2}{*}{$P$ value } \\
\hline & First recording & Last recording & & \\
\hline ICS (n=204) & $2.75(0.94)$ & $2.78(0.97)$ & 0.03 (-0.03 to 0.09$)$ & 0.369 \\
\hline $\mathrm{ICS}+\mathrm{BB}(\mathrm{n}=43)$ & $2.58(0.82)$ & $2.71(0.87)$ & $0.13(-0.02$ to 0.28$)$ & 0.086 \\
\hline ICS+LABA $(n=459)$ & $2.61(0.94)$ & $2.71(0.97)$ & $0.10(0.05$ to 0.14$)$ & $<0.001$ \\
\hline$I C S+L A B A+B B(n=89)$ & $2.63(0.89)$ & $2.69(0.87)$ & $0.06(-0.05$ to 0.15$)$ & 0.287 \\
\hline ICS+LABA+Tio $(n=753)$ & $2.46(0.89)$ & $2.48(0.84)$ & 0.02 (-0.01 to 0.06$)$ & 0.241 \\
\hline ICS+LABA+Tio+BB $(n=88)$ & $2.40(0.88)$ & $2.50(0.89)$ & 0.10 (-0.01 to 0.20$)$ & 0.08 \\
\hline LABA or Tio (no ICS) $(n=197)$ & $2.67(0.93)$ & $2.66(0.93)$ & $0.01(-0.07$ to 0.05$)$ & 0.767 \\
\hline BB (no ICS) (n=276) & $2.91(0.84)$ & $2.80(0.89)$ & $0.11(0.05$ to 0.16$)$ & $<0.001$ \\
\hline ICS+Tio $(n=81)$ & $2.48(0.81)$ & $2.59(0.75)$ & $0.11(0.01$ to 0.20$)$ & 0.043 \\
\hline$(\mathrm{LABA}$ or Tio $)+B B(n=47)$ & $2.77(0.93)$ & $2.82(0.95)$ & $0.05(-0.05$ to 0.17$)$ & 0.297 \\
\hline Controlł $(n=475)$ & $2.90(0.96)$ & $2.86(0.95)$ & $-0.04(-0.09$ to -0.02$)$ & 0.041 \\
\hline
\end{tabular}

*Treatments: ICS=inhaled corticosteroid, $B B=\beta$ blocker, $L A B A=$ long acting $\beta$ agonist, Tio=tiotropium. $† F V C=$ forced vital capacity (litres).

$\ddagger$ Control=treatment only with short acting $\beta$ agonists with or without short acting antimuscarinic agent.

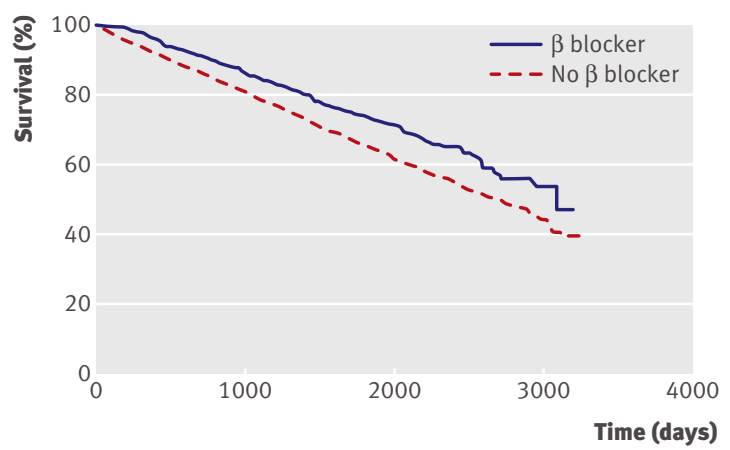

Fig 1| Kaplan-Meier estimate of probability of survival among patients with COPD by use of $\beta$ blockers

only inhaled therapy with either short acting $\beta$ agonists (salbutamol, terbutaline) or short acting antimuscarinic agent (ipratropium). Two or more sequential prescriptions were required for patients to be stratified into differing treatment groups.

Cox proportional hazard regression analysis was then used to calculate crude and adjusted hazard ratios for all cause mortality, hospital admissions due to respiratory disease, and emergency oral corticosteroid use dependent on treatment groups in reference to the control group. This was repeated for death from myocardial infarction and death from COPD as surrogate markers of cardiac and respiratory mortality.

Subgroup analyses were also performed for hospital admissions related to respiratory disease, specifically due to COPD exacerbation. When calculating hazard ratios for all cause mortality, we censored patient data when they were lost to follow-up or reached the end of the study period (January 2010). For hospital admissions and oral corticosteroid use, we calculated treatment groups using prescription data before the respective event occurring, with censoring as described above.

Adjusted hazard ratios for mortality were calculated after correction with these covariates: cardiovascular and respiratory hospital admissions, diabetes, smoking, age at diagnosis, sex, cardiac drug use, $\mathrm{FEV}_{1}$, resting $\mathrm{SaO}_{2}$, and deprivation index. Additional models were developed to calculate adjusted hazard ratios, death from COPD or from myocardial infarction, hospital admissions due to respiratory disease, hospital admissions due to COPD, and oral corticosteroid use. All hazard ratios were calculated from Cox regression models after forced entry of all available covariates to reduce residual confounding.

For all tests, a two sided $\mathrm{P}$ value of $<0.05$ was considered significant. Analyses were performed using SPSS version 17.0.

\section{RESULTS}

A total of 6345 patients were identified through the TARDIS database. Within this cohort, 5977 were $>50$ years old and were included in our analysis. Patients were excluded from the analysis if they had a history of malignancy before entry into TARDIS. 


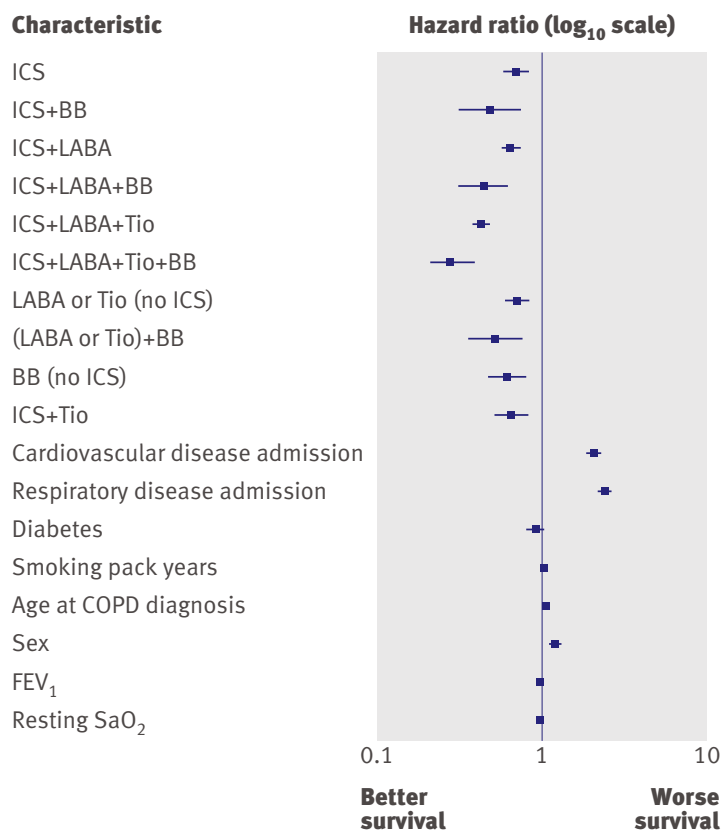

$I C S=$ inhaled corticosteroid, $B B=\beta$ blocker, $L A B A=$ long acting $\beta$ agonist, Tio=tiotropium, $\mathrm{FEV}_{1}=$ forced expiratory volume in one second, $\mathrm{SaO}_{2}=$ arterial oxygen saturation

Fig 2 Adjusted hazard ratios for all cause mortality among patients with COPD in reference to the control group (who received only inhaled therapy with short acting $\beta$ agonists or antimuscarinics)

Stratified by the Global Initiative for Chronic Obstructive Lung Disease (GOLD) spirometry classification, 897 patients $(15 \%)$ were stage 1 with mean $\mathrm{FEV}_{1}$ 90.8\% (SD 9.4), 3287 (55\%) were stage 2 with $\mathrm{FEV}_{1}$ $64.8 \%(8.3), 1494(25 \%)$ were stage 3 with $\mathrm{FEV}_{1}$ $40.9 \%$ (5.6), and $299(5 \%)$ were stage 4 with $\mathrm{FEV}_{1}$ $24.8 \%$ (4.6). Mean (SD) length of follow-up was 4.35 (2.28) years. The patients' mean $(\mathrm{SD})$ age at diagnosis of COPD (time of entry into TARDIS database) was 69.1 (9.4) years, and $3048(51 \%)$ were male. Of the $\beta$ blockers used, $720(88 \%)$ were cardioselective. All patients, including the control group, were receiving short acting $\beta$ agonists with or without ipratropium. Table 1 shows the patients' characteristics at study entry.

\section{Pulmonary function}

We made a subgroup analysis of 2712 patients for whom 6639 serial measurements of $\mathrm{FEV}_{1}$ and forced vital capacity (FVC) were available. Those patients being prescribed triple therapy with inhaled corticosteroids, long acting $\beta$ agonists, and tiotropium had the lowest $\mathrm{FEV}_{1}$, in keeping with increased disease severity. The addition of a $\beta$ blocker had no deleterious impact when added to a regimen that included a long acting bronchodilator or inhaled corticosteroid (such as inhaled corticosteroids and long acting $\beta$ agonists or inhaled corticosteroids, long acting $\beta$ agonists, and tiotropium) (tables 2 and 3). Moreover, when $\mathrm{FEV}_{1}$ values at the start of the study period were compared
Table $4 \mid$ Risk of all cause mortality among patients with COPD by treatment regimen* and covariates

Characteristic

Adjusted hazard ratios $(95 \% \mathrm{Cl}) \dagger$

Treatment groups*

\begin{tabular}{ll}
\hline ICS+LABA+Tio+BB & $0.28(0.21$ to 0.39$)$ \\
\hline ICS+LABA+Tio & $0.43(0.38$ to 0.48$)$ \\
\hline ICS+LABA+BB & $0.44(0.31$ to 0.62$)$ \\
\hline ICS+LABA & $0.64(0.57$ to 0.74$)$ \\
\hline ICS+BB & $0.48(0.31$ to 0.74$)$ \\
\hline ICS & $0.69(0.58$ to 0.83$)$ \\
\hline ICS +Tio & $0.61(0.47$ to 0.80$)$ \\
\hline LABA or Tio (no ICS)+BB & $0.52(0.36$ to 0.76$)$ \\
\hline LABA or Tio (no ICS) & $0.71(0.59$ to 0.84$)$ \\
\hline BB (no ICS) & $0.65(0.51$ to 0.83$)$ \\
\hline Covariates used in Cox regression model
\end{tabular}

Covariates used in Cox regression model

History of hospital admission:

\begin{tabular}{ll}
\hline For cardiovascular disease & $2.04(1.84$ to 2.27$)$ \\
\hline For respiratory disease & $2.38(2.16$ to 2.62$)$ \\
\hline Age at study entry (years) & $1.05(1.05$ to 1.06$)$ \\
\hline Sex (male) & $1.19(1.09$ to 1.31$)$ \\
\hline Smoking (pack years) & $1.01(1.00$ to 1.01$)$ \\
\hline History of diabetes & $0.91(0.80$ to 1.03$)$ \\
\hline FEV $_{1} \ddagger$ & $0.98(0.97$ to 0.98$)$ \\
\hline Resting $\mathrm{SaO}_{2} \S$ & $0.99(0.99$ to 1.00$)$ \\
\hline Deprivation indexT: & \\
\hline 1 & $0.99(0.89$ to 1.11$)$ \\
\hline 2 & $1.02(0.88$ to 1.19$)$ \\
\hline 3 & $0.88(0.76$ to 1.02$)$ \\
\hline 4 & $0.85(0.73$ to 1.00$)$ \\
\hline Cardiovascular drugs: & \\
\hline Aspirin & $0.80(0.73$ to 0.88$)$ \\
\hline Statins & $0.89(0.81$ to 0.97$)$ \\
\hline ACE inhibitors & $0.79(0.72$ to 0.88$)$ \\
\hline Calcium channel blockers & $0.71(0.64$ to 0.78$)$ \\
\hline
\end{tabular}

*Treatments: ICS=inhaled corticosteroid, BB= $\beta$ blocker, $L A B A=$ long acting $\beta$ agonist, Tio=tiotropium.

†Adjusted hazard ratios relative to the control group, which received only treatment with short acting $\beta$ agonists or antimuscarinic agent.

$\ddagger F E V_{1}=$ forced expiratory volume in one second, given as percentage predicted for age, sex, and race.

$\S \mathrm{SaO}_{2}=$ arterial oxygen saturation.

ПHealth board specific Scottish Index of Multiple Deprivation (HBSIMD), rated on a scale of $1-4$ (1=most deprived, $4=$ least deprived).

with those at the end, there was no clinically significant deterioration in any treatment group that included a $\beta$ blocker (a clinically significant difference regarded as a $30 \mathrm{~mL} /$ year reduction in $\mathrm{FEV}_{1}{ }^{23}$ ).

\section{All cause mortality}

The Kaplan-Meier analysis and log rank testing to evaluate the impact of $\beta$ blockers on survival showed a significant improvement in overall survival for the 819 patients who received $\beta$ blockers compared with those who did not $\left(\chi^{2}\right.$ test $\left.18.97, \mathrm{P}<0.001\right)$ (fig 1$)$. After matched propensity scoring analysis, to balance associated covariates between groups, we found that $\beta$ blocker use was associated with a $22 \%$ reduction in mortality (hazard ratio 0.78 (95\% confidence interval 0.67 to 0.92$)$ ). 
Table $5 \mid$ Risk of death from myocardial infarction and from COPD among patients with COPD by treatment regimen*

\begin{tabular}{llc} 
& \multicolumn{2}{c}{ Adjusted hazard ratios $(95 \% \mathrm{CI}) \dagger$} \\
\cline { 2 - 3 } Treatment group* & $\begin{array}{c}\text { Death from myocardial } \\
\text { infarction }(\mathrm{n}=288)\end{array}$ & Death from COPD (n=625) \\
\hline ICS+LABA+Tio+BB & $0.25(0.11$ to 0.58$)$ & $0.39(0.20$ to 0.78$)$ \\
\hline ICS+LABA+Tio & $0.44(0.31$ to 0.62$)$ & $0.30(0.24$ to 0.38$)$ \\
\hline ICS+LABA+BB & $0.49(0.27$ to 0.90$)$ & $0.23(0.09$ to 0.64$)$ \\
\hline ICS+LABA & $0.53(0.37$ to 0.76$)$ & $0.52(0.40$ to 0.68$)$ \\
\hline ICS+BB & $0.46(0.19$ to 1.13$)$ & $0.25(0.06$ to 0.99$)$ \\
\hline ICS & $0.80(0.51$ to 1.27$)$ & $0.45(0.32$ to 0.65$)$ \\
\hline ICS +Tio & $0.63(0.29$ to 1.37$)$ & $0.39(0.25$ to 0.61$)$ \\
\hline LABA or Tio $($ no ICS)+BB & $0.54(0.25$ to 1.16$)$ & $0.38(0.12$ to 1.20$)$ \\
\hline LABA or Tio $($ no ICS) & $1.09(0.66$ to 1.81$)$ & $0.42(0.30$ to 0.60$)$ \\
\hline BB (no ICS) & $0.67(0.41$ to 1.10$)$ & $0.88(0.32$ to 2.38$)$ \\
\hline
\end{tabular}

*Treatments: ICS=inhaled corticosteroid, $B B=\beta$ blocker, $L A B A=$ long acting $\beta$ agonist, Tio=tiotropium.

†Adjusted hazard ratios relative to the control group, which received only treatment with short acting $\beta$ agonists or antimuscarinic agent. Covariates used in Cox regression model were history of cardiovascular and respiratory disease, age, sex, smoking, history of diabetes, and deprivation.

Comparing cardioselective $\beta$ blockers with nonselective $\beta$ blockers, we found no significant difference between groups $\left(\chi^{2}\right.$ test $\left.0.77, \mathrm{P}=0.378\right)$.

A total of 2005 patients died during the study period, equating to an annual mortality of $34 \%$. We calculated Cox proportional hazards ratios for each treatment group based on stepwise management for COPD. At each comparison, the adjusted hazard ratio for treatment groups including a $\beta$ blocker were lower than the respective treatment group without a $\beta$ blocker. Thus the crude hazard ratios for those patients taking inhaled corticosteroids, long acting $\beta$ agonists, and tiotropium with and without $\beta$ blocker were $0.38(95 \%$ confidence interval 0.28 to 0.52$)$ and 0.54 (0.48 to $0.61)$, while their adjusted hazard ratios were 0.28 (0.21 to 0.39 ) and 0.43 (0.38 to 0.48 ), respectively. Similarly, the crude hazard ratios for the patients taking inhaled corticosteroids and long acting $\beta$ agonists with and without $\beta$ blocker were 0.43 (0.31 to 0.60$)$ and 0.67 (0.59 to 0.78$)$, and their adjusted hazard ratios were 0.44 (0.31 to 0.62$)$ and 0.64 (0.57 to 0.74$)$, respectively. Finally, the crude hazard ratios for patients taking inhaled corticosteroids with and without $\beta$ blocker were 0.51 (0.33 to 0.79$)$ and $0.66(0.55$ to 0.79$)$, and their adjusted hazard ratios were 0.48 (0.31 to 0.74 ) and 0.69 (0.58 to 0.83$)$. Adjusted hazard ratios for all treatment groups and covariates used in the Cox regression model are shown in figure 2 and table 4 .

\section{Cardiac and respiratory mortality}

Of the 2005 patients who died during the study period, $288(14 \%)$ had myocardial infarction recorded as their primary cause of death and $625(32 \%)$ had COPD recorded as their primary cause. Similar benefits in reducing death from myocardial infarction and from COPD were seen when these patients were stratified by treatment group. For example, for those patients taking inhaled corticosteroids, long acting $\beta$ agonists, tiotropium, and $\beta$ blocker, the adjusted hazard ratios for death from myocardial infarction and from
COPD were 0.25 (0.11 to 0.58 ) and 0.39 (0.2 to 0.78 , respectively (see table 5).

\section{Emergency oral steroid prescription}

Of the 5977 patients in the study, $3415(57 \%)$ had at least one prescription of oral corticosteroids during the study period. The adjusted hazard ratios for oral corticosteroid prescription for those patients taking inhaled corticosteroids, long acting $\beta$ agonists, and tiotropium with and without $\beta$ blocker were 0.31 ( 0.22 to $0.43)$ and 0.68 (0.61 to 0.75$)$. The adjusted hazard ratios for oral corticosteroids for patients taking inhaled corticosteroids and long acting $\beta$ agonists with and without $\beta$ blocker were 0.46 (0.34 to 0.63 ) and 0.93 (0.85 to 1.03). The adjusted hazard ratios for patients taking inhaled corticosteroids with and without $\beta$ blocker were 0.51 (0.39 to 0.69 ) and 0.77 (0.69 to 0.87$)$. The adjusted hazard ratios for covariates used in the Cox regression model are shown in figure 3 and listed in table 6 .

\section{Hospital admissions for respiratory disease}

Of the study patients, 1608 (27\%) had at least one hospital admission due to respiratory disease during the study period. The adjusted hazard ratios for such admission for those patients taking inhaled corticosteroids, long acting $\beta$ agonists, and tiotropium with and without $\beta$ blocker were $0.32(0.22$ to 0.44$)$ and 0.70 (0.61 to 0.80$)$. The adjusted hazard ratios for patients taking inhaled corticosteroids and long acting $\beta$ agonists with and without $\beta$ blocker were 0.39 ( 0.26 to $0.60)$ and 0.82 (0.70 to 0.96$)$. The adjusted hazard ratios for inhaled corticosteroids with and without $\beta$ blocker were 0.36 (0.22 to 0.58 ) and 0.79 (0.66 to 0.95 ). Adjusted hazard ratios for covariates used in the Cox regression model are shown in figure 4 and listed in table 7 .

\section{Hospital admissions for COPD}

Of those who had a hospital admission due to respiratory disease, $1094(68 \%)$ had a primary coded diagnosis of COPD exacerbation. Similar trends of improvement with $\beta$ blockers were seen as with all hospital admissions due to respiratory disease. The adjusted hazard ratio for hospital admission due to COPD for patients taking inhaled corticosteroids, long acting $\beta$ agonists, and tiotropium with and without $\beta$ blocker were 0.25 (0.14 to 0.42$)$ and 0.77 (0.65 to 0.91). The adjusted hazard ratios for patients taking inhaled corticosteroids and long acting $\beta$ agonists with and without $\beta$ blocker were 0.37 (0.22 to 0.64 ) and 0.81 (0.67 to 0.97). The adjusted hazard ratios for inhaled corticosteroids with and without $\beta$ blocker were 0.24 (0.20 to 0.49$)$ and 0.69 (0.54 to 0.87 ).

\section{DISCUSSION}

Through matched propensity scoring analysis, our data suggest a $22 \%$ overall reduction in all cause mortality for patients with COPD when their inhaled treatment regimen includes $\beta$ blockers. Importantly, our data also suggest there may be benefits when $\beta$ blockers 
are added to established stepwise inhaled treatment regimens for COPD in reducing all cause mortality. Our Cox proportional hazard regression analyses have shown that the additive benefits of $\beta$ blockers were independent of other cardiovascular drugs and history of overt cardiovascular disease (ischaemic heart disease, heart failure, peripheral vascular disease). These findings suggest that $\beta$ blockers have effects on reducing mortality in COPD in addition to the benefits gained by reducing cardiovascular risk.

The baseline demographics of our treatment groups showed similar levels of social deprivation. Deprivation is known to influence mortality, and, with regard to use of $\beta$ blockers to treat heart failure, patients with worse deprivation are less likely to be treated. ${ }^{24} \mathrm{We}$ used the Scottish Index of Multiple Deprivation to calculate the deprivation score in our study: $6.9 \%$ of the most deprived areas in Scotland are covered by Tayside Health Board. ${ }^{25}$

\section{Comparison with other studies}

Previous studies have focused on the presence or absence of $\beta$ blockers and their influence on mortality. ${ }^{15}$ Rutten et al found that the benefit on mortality seen with $\beta$ blockers was preserved in those individuals who were concurrently prescribed two or more pulmonary drugs or who were using inhaled $\beta_{2}$ agonists or antimuscarinics. However, their analysis did not stratify patients according to stepwise treatment regimens, in particular for long acting $\beta$ agonists and long acting antimuscarinics. We believe this issue is

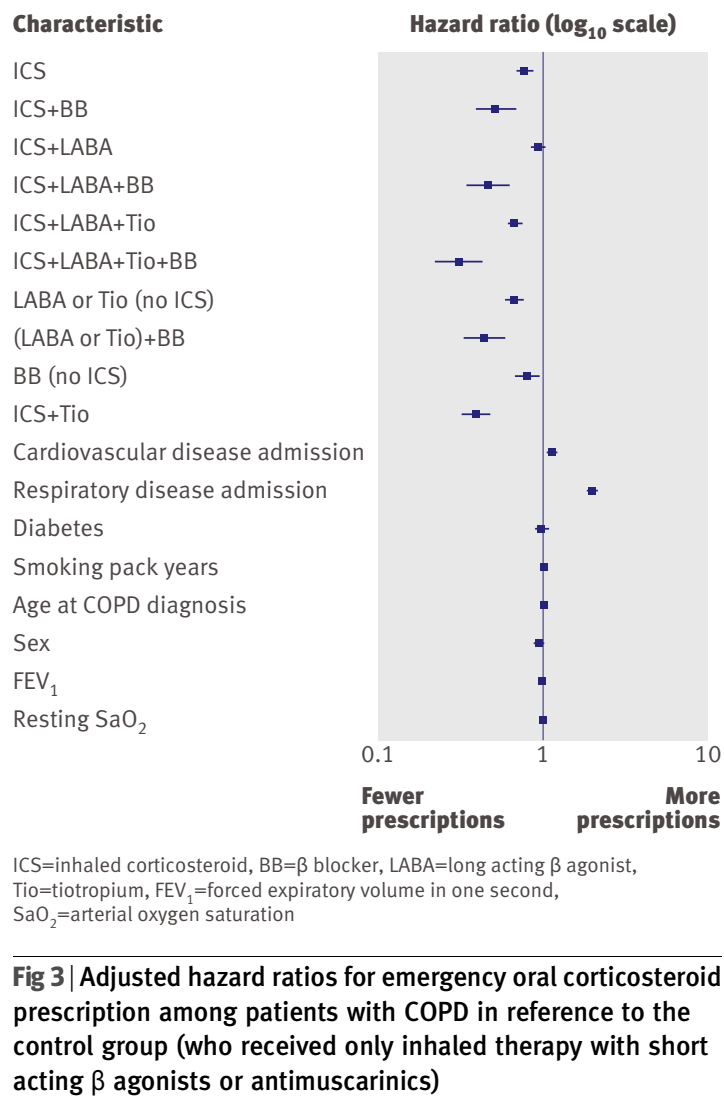

pertinent given the potential for co-prescription of drugs with agonist and antagonist properties with theoretical interactions.

$\mathrm{FEV}_{1}$ has previously been shown to decline over time. ${ }^{26}$ Using a $30 \mathrm{~mL} /$ year reduction (as observed in the placebo limb of the UPLIFT study ${ }^{23}$ ) as our reference, we found no clinically significant decline in mean $\mathrm{FEV}_{1}$ over time in each treatment group. Within treatment groups, decline in $\mathrm{FEV}_{1}$ was observed in individual patients, but the percentage of patients showing a decline was consistent among the treatment groups.

In line with previous studies, we found a reduction in all cause mortality among patients with COPD who were taking statins and angiotensin converting enzyme inhibitors. ${ }^{2728}$ As expected, our data showed significant mortality reductions with use of cardiovascular drugs (hazard ratios with aspirin 0.8 (95\% confidence interval 0.73 to 0.88 ), statins 0.89 (0.81 to 0.97 ), angiotensin converting enzyme inhibitors 0.79 ( 0.72 to 0.88$)$ and calcium channel blockers 0.71 (0.64 to 0.78$)$ ). These findings show the importance of recognising

Table 6 |Risk of emergency oral corticosteroid prescription among patients with COPD by treatment regimen* and covariates

\begin{tabular}{|c|c|}
\hline Characteristic & Adjusted hazard ratios $(95 \% \mathrm{Cl}) \dagger$ \\
\hline \multicolumn{2}{|l|}{ Treatment groups* } \\
\hline ICS+LABA+Tio+BB & 0.31 (0.22 to 0.43$)$ \\
\hline ICS+LABA+Tio & $0.68(0.61$ to 0.75$)$ \\
\hline $\mathrm{ICS}+\mathrm{LABA}+\mathrm{BB}$ & $0.46(0.34$ to 0.63$)$ \\
\hline ICS+LABA & 0.93 (0.85 to 1.03$)$ \\
\hline ICS+BB & 0.51 (0.39 to 0.69$)$ \\
\hline ICS & 0.77 (0.69 to 0.87$)$ \\
\hline ICS + Tio & 0.81 (0.68 to 0.96$)$ \\
\hline LABA or Tio (no ICS)+BB & 0.44 (0.33 to 0.59$)$ \\
\hline LABA or Tio (no ICS) & 0.67 (0.59 to 0.76$)$ \\
\hline BB (no ICS) & $0.39(0.32$ to 0.48$)$ \\
\hline \multicolumn{2}{|c|}{ Covariates used in Cox regression model } \\
\hline \multicolumn{2}{|l|}{ History of hospital admission: } \\
\hline For cardiovascular disease & 1.14 (1.06 to 1.22$)$ \\
\hline For respiratory disease & 2.01 (1.87 to 2.16$)$ \\
\hline History of diabetes & $0.99(0.90$ to 1.10$)$ \\
\hline Smoking (pack years) & $1.00(0.99$ to 1.01$)$ \\
\hline Age at study entry (years) & 1.01 (1.00 to 1.02$)$ \\
\hline Sex (male) & 0.95 (0.89 to1.02) \\
\hline $\mathrm{FEV}_{1} \ddagger$ & 1.00 (0.99 to 1.01$)$ \\
\hline Resting $\mathrm{SaO}_{2} \S$ & 1.01 (1.01 to 1.02 ) \\
\hline \multicolumn{2}{|l|}{ Deprivation indexף: } \\
\hline 1 & 1.01 (0.93 to 1.10$)$ \\
\hline 2 & $1.03(0.91$ to 1.15$)$ \\
\hline 3 & 0.94 (0.84 to 1.06$)$ \\
\hline 4 & $0.92(0.82$ to 1.04$)$ \\
\hline
\end{tabular}

*Treatments: ICS=inhaled corticosteroid, $B B=\beta$ blocker, $L A B A=$ long acting $\beta$ agonist, Tio=tiotropium.

†Adjusted hazard ratios relative to the control group, which received only treatment with short acting $\beta$ agonists or antimuscarinic agent.

$\mathrm{fFEV}_{1}=$ forced expiratory volume in one second, given as percentage predicted for age, sex, and race.

$\S \mathrm{SaO}_{2}=$ arterial oxygen saturation.

『Health board specific Scottish Index of Multiple Deprivation (HBSIMD), rated on a scale of $1-4$ (1=most deprived, $4=$ least deprived). 


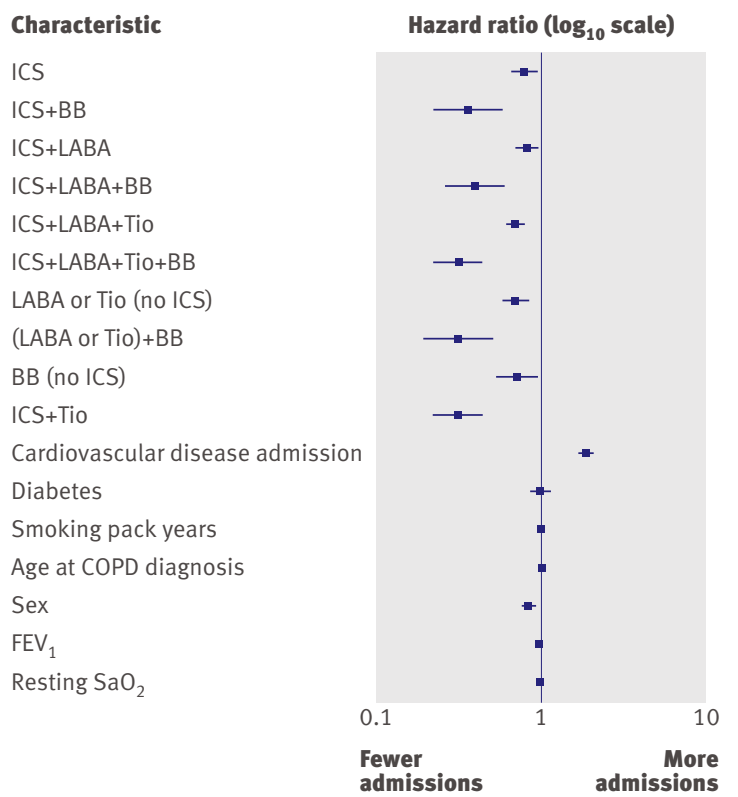

ICS=inhaled corticosteroid, $B B=\beta$ blocker, $L A B A=$ long acting $\beta$ agonist, Tio=tiotropium, FEV =forced expiratory volume in one second, $\mathrm{SaO}_{2}=$ arterial oxygen saturation

Fig 4 | Adjusted hazard ratios for hospital admissions due to respiratory disease among patients with COPD in reference to the control group (who received only inhaled therapy with short acting $\beta$ agonists or antimuscarinics)

that patients with COPD have a high risk of developing cardiovascular disease.

\section{Meaning of the study}

In terms of the benefit of adding $\beta$ blockers to stepwise inhaled therapy, our data showed the same trends for all cause mortality, oral corticosteroid prescriptions, and hospital admissions, which adds support to the value of using $\beta$ blockers in COPD. Although it could be suggested that the reduction observed in all cause mortality with $\beta$ blockers is attributable to their cardiovascular effects, similar benefits were seen in reducing deaths from COPD and deaths from myocardial infarction, although some hazard ratios within groups failed to reach statistical significance. These observations (together with the reductions in hospital admissions and emergency oral corticosteroid use) cannot easily be explained by simply improving cardiovascular risk.

This raises the question of whether $\beta$ blockers confer independent beneficial effects in COPD, as has been suggested in asthma. ${ }^{29}$ One possibility is that up-regulation of $\beta_{2}$ adrenoceptors by chronic $\beta$ blockade may improve the effectiveness of $\beta_{2}$ agonists. Despite most of the $\beta$ blockers in our study being relatively cardioselective, drugs such as atenolol and bisoprolol have been shown to exert significant $\beta_{2}$ adrenoceptor antagonism even at therapeutic doses, which may result in $\beta_{2}$ adrenoceptor up-regulation. Thus, up-regulation of $\beta_{2}$ adrenoceptors by cardioselective $\beta$ blockers seems plausible. In this regard, we did not see any worsening of $\mathrm{FEV}_{1}$ or $\mathrm{FVC}$ when analysing the effect of addition of $\beta$ blockers to treatment regimens that included long acting $\beta$ agonists. Ind et al have shown that antimuscarinic drugs prevent $\beta$ blocker induced bronchoconstriction in asthmatic patients. ${ }^{30}$ This would suggest a rationale for using tiotropium when prescribing a $\beta$ blocker for a patient with COPD, aside from the known benefits of tiotropium on exacerbations and symptoms. $^{23}$

\section{Strength and limitations of study}

TARDIS is a COPD database routinely used to guide COPD management in Tayside. The advantage of using this disease specific database is that all patients have a diagnosis of COPD made by a primary or secondary care physician on the basis of Global Initiative for Chronic Obstructive Lung Disease (GOLD) guidelines. Since 2001, patients with COPD have been invited to be included in our database, and TARDIS has been used as the basis for previous published COPD research, thereby providing us with an unselected community population of COPD patients for analysis. $^{31}$

\section{Table $7 \mid$ Risk of hospital admissions due to respiratory disease among patients with COPD by treatment regimen* and covariates}

\begin{tabular}{|c|c|}
\hline Characteristic & Adjusted hazard ratios $(95 \% \mathrm{Cl}) \dagger$ \\
\hline \multicolumn{2}{|l|}{ Treatment groups* } \\
\hline$I C S+L A B A+T i o+B B$ & $0.32(0.22$ to 0.44$)$ \\
\hline ICS+LABA+Tio & $0.70(0.61$ to 0.80$)$ \\
\hline ICS+LABA+BB & $0.39(0.26$ to 0.60$)$ \\
\hline ICS+LABA & $0.82(0.70$ to 0.96$)$ \\
\hline $\mathrm{ICS}+\mathrm{BB}$ & $0.36(0.22$ to 0.58$)$ \\
\hline ICS & 0.79 (0.66 to 0.95$)$ \\
\hline ICS +Tio & $0.71(0.53$ to 0.96$)$ \\
\hline LABA or Tio (no ICS)+BB & $0.31(0.19$ to 0.51$)$ \\
\hline LABA or Tio (no ICS) & $0.70(0.58$ to 0.85$)$ \\
\hline BB (no ICS) & $0.31(0.22$ to 0.44$)$ \\
\hline \multicolumn{2}{|c|}{ Covariates used in Cox regression model } \\
\hline $\begin{array}{l}\text { History of hospital admission for } \\
\text { cardiovascular disease }\end{array}$ & 1.87 (1.69 to 2.09$)$ \\
\hline History of diabetes & 0.99 (0.87 to 1.14$)$ \\
\hline Smoking (pack years) & $1.00(0.99$ to 1.01$)$ \\
\hline Age at study entry (years) & 1.01 (1.01 to 1.02$)$ \\
\hline Sex (male) & $0.84(0.76$ to 0.93$)$ \\
\hline $\mathrm{FEV}_{1} \ddagger$ & $0.98(0.97$ to 0.99$)$ \\
\hline Resting $\mathrm{SaO}_{2} \S$ & 0.99 (0.98 to 1.01$)$ \\
\hline \multicolumn{2}{|l|}{ Deprivation indexף: } \\
\hline 1 & $1.07(0.95$ to 1.21$)$ \\
\hline 2 & 1.26 (1.07 to 1.48$)$ \\
\hline 3 & $1.04(0.88$ to 1.23$)$ \\
\hline 4 & 0.92 (0.77 to 1.11$)$ \\
\hline
\end{tabular}

*Treatments: ICS=inhaled corticosteroid, $B B=\beta$ blocker, $\mathrm{LABA}=$ long acting $\beta$ agonist, Tio=tiotropium.

†Adjusted hazard ratios relative to the control group, which received only treatment with short acting $\beta$ agonists or antimuscarinic agent.

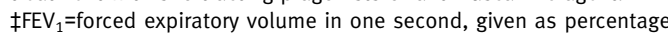
predicted for age, sex, and race.

$\S \mathrm{SaO}_{2}=$ arterial oxygen saturation.

THealth board specific Scottish Index of Multiple Deprivation (HBSIMD), rated on a scale of 1-4 (1=most deprived, $4=$ =least deprived). 


\section{WHAT IS ALREADY KNOWN ON THIS TOPIC}

Despite the clear benefits of $\beta$ blocker use in cardiovascular disease, their use is avoided in patients with concurrent chronic obstructive pulmonary disease (COPD) because of concerns about bronchospasm and the potential to block the bronchodilating effects of $\beta$ agonist inhalers

Studies have suggested that $\beta$ blockers may reduce mortality and exacerbations in COPD patients, but do not assess these benefits when stratified by concurrent established COPD drug treatments

\section{WHAT THIS STUDY ADDS}

$\beta$ blockers (predominantly cardioselective) reduced mortality and COPD exacerbations when added to stepwise inhaled therapy for COPD (including long acting $\beta$ agonists and antimuscarinics) in addition to the benefits attributable to addressing cardiovascular risk

The benefits observed occurred without adverse effects on pulmonary function

These data support the use of $\beta$ blockers in patients with COPD

This is a retrospective and observational study, so our results should be interpreted with caution. Confounding by indication is a limitation when performing observational studies of this nature. As we used a disease specific database for patient identification, we do not know the specific indication for $\beta$ blocker prescription. In order to address this, we used a Cox proportional hazard regression model that corrected for all available influential covariates. We evaluated the effects of $\beta$ blockers on all cause mortality independently of cardiovascular outcomes, including cardiac drug prescription and overt cardiovascular disease as measured by hospital admissions due to ischaemic heart disease, heart failure, or peripheral vascular disease (although a history of hypertension was unavailable for analysis from our database). Furthermore, when assessing the impact of $\beta$ blocker use on all cause mortality, we performed a matched propensity scoring analysis, which is designed to minimise the effects of confounding by indication. ${ }^{32}$

We chose a minimum age of 50 years in order to alleviate any concerns that younger patients might be regarded as asthmatic. An age cut-off of 45 years and above has been use in previous COPD observational studies. ${ }^{15}$ Furthermore, when analysing all the patients in our dataset regardless of age $(\mathrm{n}=6345)$, we saw similar trends in survival as with our study cohort of 5977. For example, among patients taking inhaled corticosteroids, long acting $\beta$ agonists, tiotropium, and $\beta$ blockers, the adjusted hazard ratio for all cause mortality was $0.33(0.24$ to 0.44$)$ in the full dataset compared with 0.28 (0.21 to 0.39$)$ in our study population. From these data, we believe patient exclusion has not biased our study results.

\section{Conclusions and policy implications}

We have shown that $\beta$ blockers (predominantly cardioselective) may confer reductions in mortality, exacerbations, and hospital admissions in patients with COPD, in addition to the benefits attributable to addressing cardiovascular risk. These additive benefits were seen across a spectrum of inhaled stepwise therapy, including inhaled corticosteroids, long acting $\beta$ agonists, and long acting antimuscarinics, and did not result in any worsening of pulmonary function in our study cohort. Our study supports the use of $\beta$ blockers in COPD patients.

We thank Peter Donnan, professor of epidemiology and biostatistics, University of Dundee, for his advice and support.

Contributors: All authors contributed to the study design and data interpretation. PMS, SIWL, and DHJE undertook the data analysis and validation. PMS and BJL wrote the first draft of the manuscript, and all authors contributed to the final draft. BJL is guarantor for the study. Data were collated and provided to the authors by the Health Informatics Centre (a partnership between the University of Dundee, NHS Tayside, and the Information Services Division of NHS National Services Scotland). Funding: This study was funded by the University of Dundee. The university had no influence over the design and conduct of the study; collection, management, analysis, and interpretation of the data; or preparation, review, or approval of the manuscript.

Competing interests: All authors have completed the Unified Competing Interest form at www.icmje.org/coi_disclosure.pdf (available on request from the corresponding author) and declare: no support from any organisation for the submitted work; no financial relationships with any organisations that might have an interest in the submitted work in the previous 3 years; no other relationships or activities that could appear to have influenced the submitted work.

Ethical approval: The study was approved by the Tayside Medical Research Ethics Committee.

Data sharing: No additional data available.

1 Sin DD, Man SF. Why are patients with chronic obstructive pulmonary disease at increased risk of cardiovascular diseases? The potential role of systemic inflammation in chronic obstructive pulmonary disease. Circulation 2003;107:1514-9.

2 Olenchock BA, Fonarow GG, Pan W, Hernandez A, Cannon CP. Current use of beta blockers in patients with reactive aimay disease who are hospitalized with acute coronary syndromes. Am J Cardiol 2009;103:295-300.

3 Gauld DR, Pain MC, Rubinfeld AR. B blocking drugs and airways obstruction. Med J Aust 1979;2:88.

4 Raine JM, Palazzo MG, Kerr JH, Sleight P. Near-fatal bronchospasm after oral nadolol in a young asthmatic and response to ventilation with halothane. BMJ 1981;282:548-9.

5 Williams IP, Millard FJ. Severe asthma after inadvertent ingestion of oxprenolol. Thorax 1980;35:160.

6 Chang CL, Mills GD, McLachlan JD, Karalus NC, Hancox RJ. Cardioselective and non-selective beta-blockers in chronic obstructive pulmonary disease: effects on bronchodilator response and exercise. Intern Med J 2010;40:193-200.

7 Van der Woude HJ, Zaagsma J, Postma DS, Winter TH, van Hulst M, Aalbers R. Detrimental effects of beta-blockers in COPD: a concern fo nonselective beta-blockers. Chest 2005;127:818-24.

8 Salpeter SR, Ormiston TM, Salpeter EE, Poole PJ, Cates CJ. Cardioselective beta-blockers for chronic obstructive pulmonary disease: a meta-analysis. Respir Med 2003;97:1094-101.

9 Van Gestel YR, Hoeks SE, Sin DD, Stam H, Mertens FW, Bax JJ, et al. Beta-blockers and health-related quality of life in patients with peripheral arterial disease and COPD. Int J Chron Obstruct Pulmon Dis 2009;4:177-83.

10 Salpeter S, Ormiston T, Salpeter E. Cardioselective beta-blockers for chronic obstructive pulmonary disease. Cochrane Database Syst Rev 2005:4:CD003566.

11 Agusti A, Calverley PM, Celli B, Coxson HO, Edwards LD, Lomas DA, et al. Characterisation of COPD heterogeneity in the ECLIPSE cohort. Respir Res 2010;11:122.

12 Zvezdin B, Milutinov S, Kojicic M, Hadnadjev M, Hromis S, Markovic M, et al. A postmortem analysis of major causes of early death in patients hospitalized with COPD exacerbation. Chest 2009;136:376-80.

13 Gottlieb SS, McCarter RJ, Vogel RA. Effect of beta-blockade on mortality among high-risk and low-risk patients after myocardial infarction. N Engl J Med 1998;339:489-97.

14 Van Gestel YR, Hoeks SE, Sin DD, Welten GM, Schouten O, Witteveen HJ, et al. Impact of cardioselective beta-blockers on mortality in patients with chronic obstructive pulmonary disease and atherosclerosis. Am J Respir Crit Care Med 2008;178:695-700.

15 Rutten FH, Zuithoff NP, Hak E, Grobbee DE, Hoes AW. Beta-blockers may reduce mortality and risk of exacerbations in patients with chronic obstructive pulmonary disease. Arch Intern Med 2010;170:880-7. 
16 Wheeldon NM, McDevitt DG, Lipworth BJ. Selectivity of antagonist and partial agonist activity of celiprolol in normal subjects. Br J Clin Pharmacol 1992;34:337-43.

17 Lipworth BJ, Irvine NA, McDevitt DG. A dose-ranging study to evaluate the beta 1-adrenoceptor selectivity of bisoprolol. Eur J Clin Pharmacol 1991;40:135-9.

18 Lipworth BJ, Irvine NA, McDevitt DG. The effects of chronic dosing on the beta 1 and beta 2-adrenoceptor antagonism of betaxolol and atenolol. Eur J Clin Pharmacol 1991;40:467-71.

19 Lipworth BJ, Brown RA, McDevitt DG. Assessment of airways, tremor and chronotropic responses to inhaled salbutamol in the quantification of beta 2-adrenoceptor blockade. Br J Clin Pharmacol 1989;28:95-102.

20 Crim C, Calverley PM, Anderson JA, Celli B, Ferguson GT, Jenkins C, et al. Pneumonia risk in COPD patients receiving inhaled corticosteroids alone or in combination: TORCH study results. Eur Respir / 2009;34:641-7.

21 Rodrigo GJ, Castro-Rodriguez JA, Plaza V. Safety and efficacy of combined long-acting beta-agonists and inhaled corticosteroids vs long-acting beta-agonists monotherapy for stable COPD: a systematic review. Chest 2009;136:1029-38.

22 Global Initiative for Chronic Obstructive Lung Disease. Global strategy for the diagnosis, management, and prevention of chronic obstructive pulmonary disease. Executive summary. Global Initiative for Chronic Obstructive Lung Disease, 2009.

23 Tashkin DP, Celli B, Senn S, Burkhart D, Kesten S, Menjoge S, et al. A 4-year trial of tiotropium in chronic obstructive pulmonary disease. $N$ Engl J Med 2008;359:1543-54.
24 Shah SM, Carey IM, DeWilde S, Richards N, Cook DG. Trends and inequities in beta-blocker prescribing for heart failure. Br J Gen Pract 2008;58:862-9.

25 The Scottish Government. Scottish index of multiple deprivation. Scottish Government, 2009.

26 Fletcher C, Peto R. The natural history of chronic airflow obstruction. BMJ 1977;1:1645-8.

27 Mancini GB, Etminan M, Zhang B, Levesque LE, FitzGerald JM, Brophy JM. Reduction of morbidity and mortality by statins, angiotensin-converting enzyme inhibitors, and angiotensin recepto blockers in patients with chronic obstructive pulmonary disease. J Am Coll Cardiol 2006;47:2554-60.

28 Soyseth V, Brekke PH, Smith P, Omland T. Statin use is associated with reduced mortality in COPD. Eur Respir J 2007;29:279-83.

29 Lipworth BJ, Williamson PA. Beta blockers for asthma: a doubleedged sword. Lancet 2009;373:104-5.

30 Ind PW, Dixon CM, Fuller RW, Barnes PJ. Anticholinergic blockade of beta-blocker-induced bronchoconstriction. Am Rev Respir Dis 1989;139:1390-4.

31 Schembri S, Anderson W, Morant S, Winter J, Thompson P, Pettitt D, et al. A predictive model of hospitalisation and death from chronic obstructive pulmonary disease. Respir Med 2009;103:1461-7.

32 D'Agostino RB Jr. Propensity score methods for bias reduction in the comparison of a treatment to a non-randomized control group. Stat Med 1998;17:2265-81.

Accepted: 08 March 2011 